\title{
In memoriam Geoffrey Neville Donaldson (1929-2002)
}

Filmhistoricus Geoffrey Neville Donaldson werd geboren in Newcastle in Australië op 29 november 1929. Over zijn leven in Australië is niet veel bekend, behalve dat hij tussen 1949 en 1954 onderwijzer was in het kleine plaatsje Comboyne East. In 1955 besloot Donaldson tegen de emigrantenstroom in op zoek te gaan naar een avontuurlijker leven in Europa.

Donaldson was een verzamelaar en elk encyclopedisch onderzoek begint natuurlijk met het verzamelen van feiten. In Australië verzamelde hij al foto's en ansichtkaarten van filmsterren. Toen hij in 1955 naar Europa reisde kwam hij onder andere in Rome terecht. Bij de Australische ambassade werd hem afgeraden om daar werk te zoeken (de werkloosheid was hoog). Bij de Romeinse filmmaatschappijen die hij afschuimde had hij meer succes: hij kon verschillende persmappen en foto's aan zijn verzameling toevoegen.

Dat Donaldson uiteindelijk in Nederland terechtkwam was behoorlijk toevallig; hij zou eigenlijk in Engeland les gaan geven. Aan dit toeval danken we zijn levenswerk. Hij had een correspondentievriendin in Nederland en het beviel hem hier. Hij ging kortstondig aan de slag als tomatenplukker en als magazijnmedewerker en verkoper bij De Bijenkorf. Uiteindelijk kwam hij terecht bij Unilever waar men zijn talenkennis en schriftelijke vaardigheden goed kon gebruiken op de afdeling octrooien. Hij vestigde zich in Rotterdam en ging later aan de allengs voller met filmdocumentatie wordende flat aan de Groenendaal samenwonen met zijn levensgezel en Algemeen Dagblad-medewerker Harry van Gunsteren.

Waarschijnlijk door zijn seksuele geaardheid had Geoffrey Donaldson feeling met de Nederlandse Diva-films waar Nederlandse filmscribenten tot dan toe aan voorbij waren gegaan. Op Donaldsons conto mag dan ook gerust de herontdekking van de zwijgende Nederlandse cinema worden gezet.

Donaldson werkte als vertaler en correspondent bij Unilever, en het is interessant te weten dat hij zijn onderzoek naar de filmgeschiedenis ook als correspondent begon. Voor Donaldson was het heel gewoon om een flink aantal brieven per dag te schrijven; hij moet er in zijn leven tienduizenden verstuurd hebben. Hij probeerde zoveel mogelijk alles per post af te doen. Zo correspondeerde hij in zijn pioniersjaren ook met het Filmmuseum en 
werden de jaargangen van oude filmtijdschriften als De Film-Wereld en De Bioscoop-Courant per aangetekende post aan hem gestuurd. Als Donaldson met het onderzoek van zo'n jaargang klaar was dan stuurde hij die weer terug naar het museum met het verzoek om de volgende. Alleen als het echt niet anders kón ging hij zijn huis uit voor zijn onderzoek. Zo interviewde hij een groot aantal mensen uit de Nederlandse zwijgende filmwereld, waaronder Nederlands eerste echte filmdiva, Annie Bos (1886-1975). Helaas zette hij deze interviews niet op de band zodat de stem van Annie voor het nageslacht verloren is gegaan. Het liefste schreef Donaldson alles en iedereen aan; hij had uiteindelijk contacten over de hele wereld. Als hij het nodig vond om voor een bepaald onderzoek of contact een taal te leren dan deed hij dat, hij leerde zichzelf bijvoorbeeld Servo-Kroatisch en schreef lange brieven in die taal aan vrienden en mensen die hij in het voormalige Joegoslavië kende in de filmwereld.

Toen Donaldson met zijn onderzoek naar de Nederlandse zwijgende filmgeschiedenis begon was er eigenlijk helemaal niets over bekend. De Nederlandsche Filmliga had in 1933 bij monde van haar voorman Henrik Scholte verklaard dat er eigenlijk vóór Joris Ivens' DE BRUG (1928) geen Nederlandse filmkunst had bestaan:

'Tot de oude zwijgende speelfilm hebben wij niets bijgedragen, kansen als in Zweden en zelfs in Tjecho-Slowakije benut werden, lieten wij voorbijgaan. Wij zochten het in pretentieuze vijfmasters, die door impresario's meer dan door filmregisseurs zeilree werden gemaakt, maar in het binnenwater van onze grenzen reeds lek sloegen en de volle zee van de internationale markt nimmer bereikten.' (H. Scholte, Nederlandsche Filmkunst, Rotterdam 1933, p. 8)

Donaldson heeft er zijn levenswerk van gemaakt om het ongelijk van Scholte te bewijzen en het kloeke boek dat uiteindelijk in 1997 van zijn hand verscheen heeft hem in het gelijk gesteld.

Zijn publicistische activiteiten zijn waarschijnlijk te omvangrijk om zelfs maar te onderzoeken. In de jaren vijftig en zestig ging hij regelmatig naar het Filmfestival van Berlijn waarover hij berichtte in het Britse tijdschrift Films and Filming. Later zou hij ook over filmhistorische onderwerpen publiceren in dat tijdschrift en ook in The Silent Picture en Films in Review. In Nederland zou Donaldson het meest schrijven voor het aanvankelijk marxisties-leninistiese (zo schreef je dat toen), later meer filmtheoretisch georiënteerde filmschrift Skrien. De verschillende oriëntaties van het blad stonden een flinke portie filmgeschiedenis niet in de weg en dus werd Donaldson een gewaardeerd medewerker. Zijn eerste artikel voor Skrien uit 


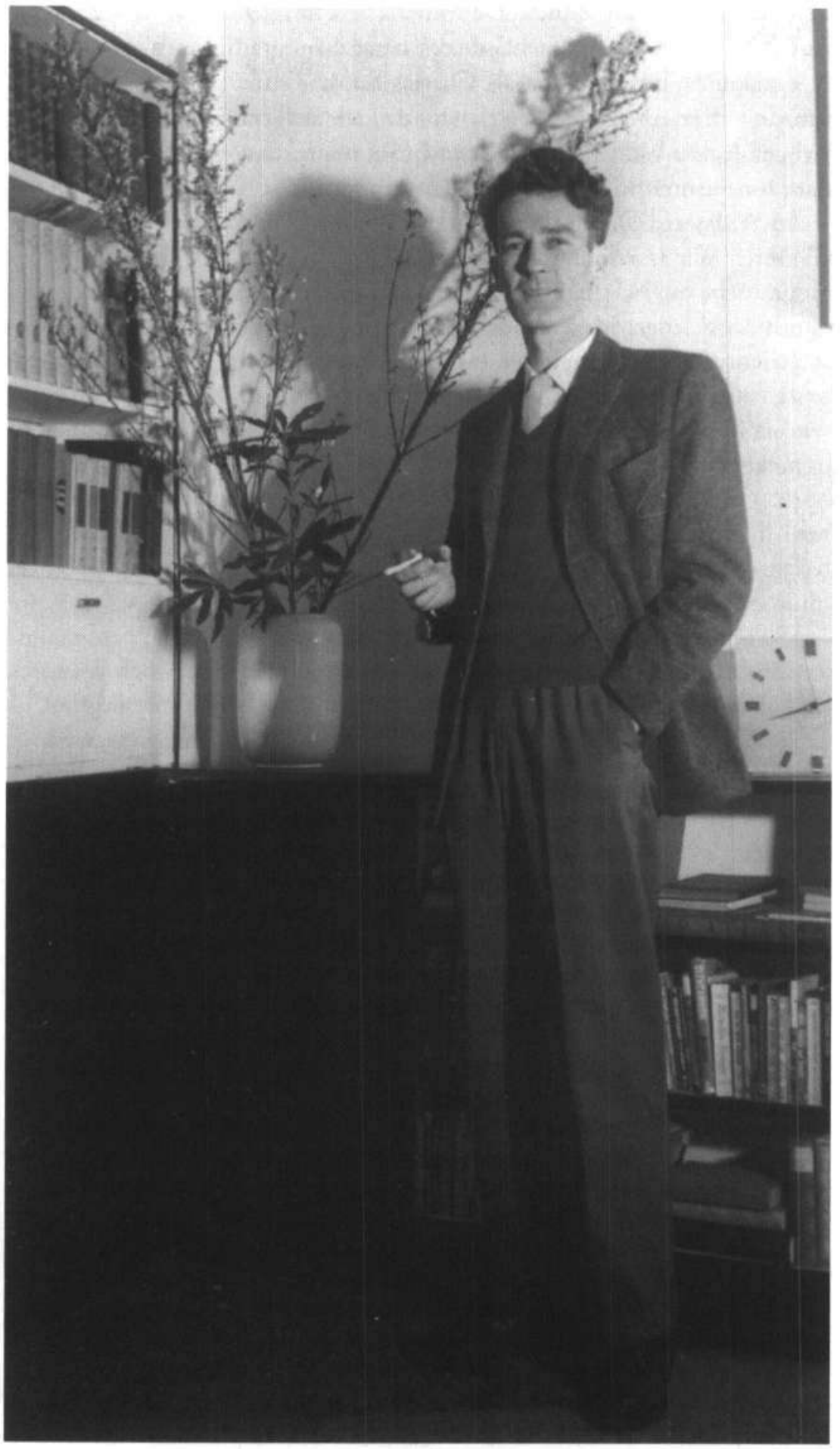

Geoff Donaldson,

ca. 1959.

Bron: Collectie

Egbert Barten 
1970 heette programmatisch 'De Nederlandse zwijgende film en de Nederlandse "filmhistorici"' en behelsde een lange opsomming van alle fouten die Nederlandse filmscribenten als Charles Boost, Emile Brumsteede, Simon van Collem en Ab van Ieperen zich tot dan toe ten koste van de Nederlandse zwijgende film hadden gepermitteerd. Het zou zeker niet de laatste keer zijn dat Donaldson kritisch uit de hoek kwam.

In 1982 werd Donaldson vaste medewerker van Skrien. Hij leverde in zijn serie 'Wie is Wie in de Nederlandse film tot 1930' voor ieder nummer biografische essays, aangevuld met filmografieën van personen die een meer of minder belangrijke rol hadden gespeeld in de vroege Nederlandse filmgeschiedenis. De serie zou lopen tot 1988. Met wetenschappelijke helderheid maar vooral met mooi geschreven artikelen haalde hij zo vergeten filmsterren als de Chileen Adelqui Migliar en de Nederlandse Mimi Boesnach opnieuw voor het voetlicht. Met een on-Nederlandse charme deed hij een oproep aan lezers van Skrien die aanvullingen en/of correcties hadden met hem in contact te treden. Dat gebeurde regelmatig, getuige verschillende naschriften. Hij was niet te beroerd om eigen falen toe te geven. Zo schreef hij in Skrien 139 onder andere:

'Bij het samenstellen van de filmografie van Margit Barnay heb ik een onbegrijpelijke, onvergeeflijke maar gelukkig niet onherstelbare fout gemaakt. Ik heb vergeten deel vII van Gerard Lamprechts naslagwerk Deutsche Stummfilme te raadplegen. Daardoor ontbreken niet minder dan veertien titels in de filmografie.'

Waarna een uitgebreide aanvulling volgde. Naast zijn pijnlijk nauwgezette research was er altijd oog voor het ongerijmde en vaak koddige in de Nederlandse filmgeschiedenis. Het fabeltje dat Donaldson vooral een feitenfreak was die niet kon schrijven moge met onderstaand citaat uit zijn artikel 'Honden in Nederlandse speelfilms' weerlegd worden:

'De volgende - en voor zover mij is bekend, laatste - zwijgende film van Nederlandse bodem waarin een hond rechtstreeks bij de actie van het verhaal is betrokken, was WEERGEvoNDEN, die Louis H. Chrispijn in 1914 voor de Filmfabriek "Hollandia" heeft geregisseerd. Gelukkig is deze film bewaard gebleven, maar in de kopie die het Nederlandse Filmmuseum in 1976-77 heeft kunnen conserveren ontbraken de originele tussentitels, zodat de naam van de daarin optredende, brutaal ogende, witte keeshond niet te achterhalen is. Gemakshalve zal ik hem hier "Keesie" noemen. De gerestaureerde kopie van WEERGEVONDEN heeft men in Arnhem tijdens de Internationale Filmweek van 1977 kunnen zien. Die voorstellingen hebben het mogelijk gemaakt een oordeel over de 
vertolking van "Keesie" te vellen. Wel, het is heel duidelijk gebleken dat de slecht gedresseerde "Keesie" nooit een doggy-Oscar had kunnen winnen, want hij geeft weinig blijk in de handeling van de film geïnteresseerd te zijn en steeds toont hij meer belangstelling voor de camera en wat er door de mensen daarachter wordt verricht. In elk geval kan hij zijn neiging om naar de camera te kijken nimmer weerstaan.' (Skrien I22, pp. I2-I3)

$\mathrm{Na}$ zijn pensionering bij Unilever eind $1989 \mathrm{kwam}$ het werk aan zijn grote boek pas goed op gang. Het Filmmuseum stimuleerde hem daarbij door hem een pc te geven en hem een stagiaire uit te lenen zodat de uitgebreide filmografische gegevens ook in digitale vorm beschikbaar kwamen. Het werk aan twee kanten (Donaldson voerde zijn gegevens in, het Filmmuseum ging alle eigen bronnen na en vulde de filmografische gegevens weer aan, opnieuw gecontroleerd door Donaldson) resulteerde in OfJoy and Sorrow (1997), een bekroning in woord maar vooral ook in beeld van Donaldsons levenslange liefde voor de Nederlandse zwijgende film. Het was niet alleen een indrukwekkend overzicht van wat er allemaal gemaakt is in de eerste 35 jaar van de Nederlandse filmgeschiedenis, maar het bevatte ook talloze gegevens over buitenlandse releases, zodat we bijvoorbeeld kunnen lezen dat de 'vijfmaster' eEN CARMEN VAN HET NOORDEN (Maurits Binger/Hans Nesna, 1919) in mei van dat jaar te zien was in de Verenigde Staten en een maand later vertoond werd in Argentinië (OfJoy and Sorrow, p. 184). De enkele jaren daarvoor overleden Filmliga-oprichter Henrik Scholte werd met kracht van woord en vooral ook van beeld van repliek gediend.

Overigens was Donaldson niet alleen actief op het gebied van de Nederlandse zwijgende film. Hij maakte onder andere ook een baanbrekend eerste overzicht van in Nederland tijdens de Tweede Wereldoorlog gemaakte speelfilms en hij hield bijvoorbeeld voor het vermaarde Lexikon zum deutschsprachigen Film van CineGraph bij waar Duitse acteurs of technici aan Nederlandse films hadden gewerkt. Ook in het Biografisch Woordenboek van Nederland komt men werk van hem tegen. Donaldson had een fabelachtig biografisch archief van vrijwel iedereen die ooit iets met Nederlandse film te maken had gehad. Vele jongere collega-onderzoekers kwamen dan ook bij hem thuis om zijn befaamde dossiers te raadplegen. Jarenlange correspondentie en uitwisseling van gegevens waren vaak het gevolg. In feite was Donaldson een heel bescheiden, zelfs verlegen man die je pas echt goed leerde kennen in zijn brieven. Vaak verontschuldigde hij zich in zo'n brief die je steevast ontving wanneer je net een middag bij hem had doorgebracht, omdat hij in de vaart van het gesprek en het slepen met archiefmateriaal helemaal was vergeten iets te drinken of iets anders aan te bieden. 
Zelf leerde ik Geoffrey in 1988 kennen toen ik net bij het Filmmuseum werkte en op een goede dag een drietal akten van een verloren gewaande Hollandia-film uit een stapel nog niet geviewde blikken tilde. Het waren - zo kon na correspondentie met Donaldson worden vastgesteld - de akten 2, 4 en de slotakte 5 van de Annie Bos-film gouden KeTENEN (Regie Maurits Binger, 1917). Het werd mijn eerste confrontatie met Nederlandse zwijgende film en er ging een wereld voor me open. Later kon ik voor mijn eigen onderzoek naar de Nederlandse filmindustrie in de jaren veertig dankbaar gebruik maken van zijn fabelachtige personendossiers. Donaldson vond die jaren veertig ook wel interessant, getuige zijn flinke verzameling van publiciteitsmateriaal van mensen als Veit Harlan, Kristina Söderbaum en anderen. Zijn materiaal over Jan Teunissen (inclusief het restant van het archief van Teunissen dat na diens dood in 1975 bij hem terecht was gekomen) stelde hij graag ter beschikking van mijn biografisch onderzoek van die 'filmtsaar'. De ordners met originele brieven en de verzamelde draaiboeken van films die Teunissen in de jaren dertig gemonteerd had kreeg je mee naar huis totdat het onderzoek klaar was.

In de enorme collectie van Donaldson bevinden zich onder andere een vier- of vijftal propvolle ordners waarin hij alles bij elkaar bracht wat hij vond over de talloze verfilmingen van de avonturenromans van zijn lievelingsauteur Henry Rider Haggard. Er zou een mooie bronnenpublicatie van te maken zijn, net als van de indrukwekkende verzameling materiaal die Donaldson bij elkaar sprokkelde over de films van D.W. Griffith. En dat zijn alleen nog maar de dingen die Geoffrey je liet zien als je er belangstelling voor had. We zullen hopen dat het Filmmuseum de indrukwekkende verzameling van Donaldson spoedig zal inventariseren zodat onderzoekers niet te lang deze Fundgrube zullen hoeven ontberen.

Donaldson ontving de NBF Cinemagiaprijs 198I voor zijn oeuvre op filmhistorisch gebied en in 1998 een speciale Gouden Kalf tijdens de Nederlands Filmfestival voor zijn mooie boek en zijn pionierswerk op het gebied van de Nederlandse filmgeschiedschrijving. Hij overleed op 72-jarige leeftijd in zijn geliefde Rotterdam, op 9 mei 2002. Ik ben zeker niet de enige die zijn gedrevenheid, zijn kritische blik maar vooral zijn vriendschap zeer zal missen.

\section{Egbert Barten}




\section{Interviews met / artikelen over G.N. Donaldson:}

'Nederlandse stomme films doen van zich spreken... door Australiër Geoff Donaldson', in: De Havenloods, 23 januari 1969.

'Australiër weet na drie jaar alles van de Nederlandse Cinema. Filmhistorie te Boek', in: Algemeen Dagblad, ca. 1969 [ongedateerd interview in knipselcollectie Filmmuseum].

'Een dramatische Verrassing in een zeventig jaar oud Filmblik. Hollywood in Holland', in: De Groene Amsterdammer, 3I augustus 1988.

'Het jaarlijkse Feest van Filmarchieven en Filmhistorici Pordenone', in: GBGNieuws, II, winter $1989 / 90$, p. 16.

'De onbetwiste Allesweter. Geoffrey Donaldson en de oude Nederlandse Film', in: Skoop, december 1990/januari 1991, p. 38-42.

'Het dameskousje met luchtgaatjes en andere meesterwerken', in: Het Parool, 14 juni 1997.

'The Slide Area: Film Book Notes', in: Classic Images 269, November 1997, p. 50. 'Ik voelde me gelukkig als verzamelaar', in: NRC Handelsblad, 25 september 1998.

\section{Belangrijkste publicaties van G.N. Donaldson}

'De Nederlandse zwijgende films en de Nederlandse "filmhistorici"', Skrien Is, september 1970, p. 3-15.

'De eerste Nederlandse speelfilms en de Gebroeders Mullens', Skrien 28, januari 1972, p. 3-I4.

'De Hollandsche Filmdiva Annie Bos 1886-1975', Skrien 76/77, juni/juli 1978, p. $40-47$.

'Speelfilms 40/45', Skrien 76/77, juni/juli 1978, p. 54-57.

'Bos, Johanna (Annie)', in: Biografisch Woordenboek van Nederland, deel I, Den Haag 1979, p. 72-73.

'Puntjes op de Kermis. Geprolongeerd: Carmine Riozzi', Skrien 94, februari 1980, p. 42-45. (samen met J.W.Drukker)

'Wie is Wie in de Nederlandse Film tot 1930' (Serie), Skrien $199 / 120$ (zomer 1982) 162 (oktober/november 1988).

'Frenkel, Theodorus Maurits (Theo Bouwmeester)', in: Biografisch Woordenboek van Nederland, deel 2, Amsterdam 1985, p. 165-167.

'Mijntje en Trijntje en haar drie film-avonturen', Jaarboek Mediageschiedenis I, Amsterdam 1989, p. 40-52.

'HER JUNGLE LOVE', 20 Jaar Skrien, april/mei 1989, p. 46-47.

OfJoy and Sorrow. A Filmography of Dutch Silent Fiction, Amsterdam 1997. 